\title{
AVALIAÇÃO DA TEMPERATURA NA PRODUÇÃO BIOTECNOLÓGICA DE ÁCIDO PROPIÔNICO
}

\author{
R.C.ROCHA ${ }^{1}$, V.C.ROCHA ${ }^{1}$,M.A.TEIXEIRA ${ }^{1}$, P.G. CASTRO ${ }^{1}$, R.N.MAEDA ${ }^{1}$, N.P.Jr ${ }^{1}$ \\ ${ }^{1}$ Universidade Federal do Rio de Janeiro, Departamento de Engenharia Bioquímica \\ E-mail para contato: renata.eq.ufrj@gmail.com
}

\begin{abstract}
RESUMO - No contexto em que há um crescimento da preocupação ambiental e um possível esgotamento do petróleo surge o interesse pela produção de alguns ácidos carboxílicos a partir de biomassa via fermentação, dentre eles o ácido propiônico. Ele é utilizado como antifúngico na alimentação humana e na conservação de grãos, aditivo em alimentos de origem animal, entre outros. O objetivo deste trabalho foi avaliar a influência da temperatura na batelada alimentada com células imobilizadas para a produção de ácido propiônico. Para isso, foi realizado o crescimento da bactéria do gênero Propionibacterium a $30^{\circ} \mathrm{C}$ e pH 7 e esta foi imobilizada de forma passiva no bagaço para posterior utilização em fermentações conduzidas em biorreatores instrumentados com controle de temperatura a $30^{\circ} \mathrm{C}$ e sem controle de temperatura. Além disso, a agitação foi mantida a $150 \mathrm{rpm}$ e o pH em 7 com variação de $+/-0,1$. A fermentação onde o parâmetro temperatura foi controlado a $30^{\circ} \mathrm{C}$ mostrou-se melhor, pois produziu cerca de $37 \mathrm{~g} / \mathrm{L}$ de ácido propiônico em detrimento de $26 \mathrm{~g} / \mathrm{L}$ produzidos no ensaio sem o controle, além de uma produtividade superior. Concluiu-se que foi possível a produção de ácido propiônico por rota biotecnológica e que o parâmetro temperatura é de suma importância na produção deste ácido utilizando células imobilizadas.
\end{abstract}

\section{INTRODUÇÃO}

Os ácidos orgânicos são de extrema importância nas indústrias química, de alimentos e farmacêutica. Os mais importantes dentre eles são os ácidos carboxílicos Uma das grandes aplicações de ácidos orgânicos é a sua utilização como intermediário na produção de plásticos biodegradáveis. Atualmente, muitos ácidos carboxílicos (incluindo os ácidos propiônico, butírico e acético) são produzidos, principalmente, por síntese química baseada no petróleo (YANG, 2008). Todavia, a preocupação com o esgotamento das reservas mundiais de matérias-primas fósseis estimulou a busca por fontes alternativas de produção de produtos petroquímicos e, neste contexto, está inserido o ácido propiônico.

Recentemente, este ácido tem chamado a atenção por ser um importante bloco de construção químico de três átomos de carbonos. Dentre as suas mais variadas aplicações, destacam-se seu papel como conservante na indústria de alimentos, aromatizante na indústria de cosméticos, além de aplicações farmacêuticas e na produção de plásticos e herbicidas (SUWANNAKHAM et al., 2006). 
Existe uma grande procura para produção de ácido propiônico por via biotecnológica, que pode ser produzido através de fermentação por meio de bactérias, tais como Selenomonas ruminantium, Propionibacterium freudenreichii, Propionibacterium acidipropionici.

As bactérias do gênero Propionibacterium são capazes de produzir o ácido propiônico em quantidades expressivas (ZHU et al., 2012). São gram positivas, imóveis, não formadoras de esporos, anaeróbias ou anaeróbias facultativas, catalase-positivas e apresentam-se sob a forma de bastonetes curtos ou de cocos, de acordo com o meio em que se encontram. A linhagem utilizada neste trabalho foi Propionibacterium acidipropionici.

Por tudo acima reportado, o objetivo do presente trabalho foi obter a máxima produção de ácido propiônico, evitando a inibição característica deste tipo de fermentação, utilizando-se da estratégia de conduzir uma batelada alimentada por pulsos em um reator com células imobilizadas no bagaço de sorgo, avaliando a influência do parâmetro temperatura.

\section{MATERIAIS E MÉTODOS}

\subsection{Procedimento experimental}

A cultura estoque de Propionibacterium acidipropionici foi armazenada em tubos criogênicos contendo $25 \%$ de glicerol e conservada a - $80^{\circ} \mathrm{C}$. Nas etapas de pré-inóculo e do inóculo foi utilizado o meio sintético Reinforced Clostridial Broth (RCB) (CORAL, 2008), contendo por litro: $10 \mathrm{~g}$ de caseína enzimática hidrolisada e de extrato de carne bovina; $3 \mathrm{~g}$ de extrato de levedura e de acetato de sódio; $5 \mathrm{~g}$ de cloreto de sódio e de dextrose; $1 \mathrm{~g}$ de amido solúvel e 0,5 de cloreto de L-cisteína. No inóculo, no entanto, houve um incremento de $10 \mathrm{~g} / \mathrm{L}$ da fonte de carbono, a xilose e de $10 \%(\mathrm{v} / \mathrm{v})$ do volume do pré-inóculo crescido pelo tempo determinado a partir da cinética realizada. Estas etapas foram realizadas em frascos de penicilina, onde gás nitrogênio foi injetado por 10 min com o auxílio da mesa inoculadora com o intuito de proporcionar a condição de anaerobiose dos ensaios. Como medida de controle do método e para garantir esta condição, em todas as etapas, utilizou-se a substância rezazurina na concentração de $1 \mathrm{~mL} / \mathrm{L}$ como indicador colorimétrico de oxigênio (na ausência de oxigênio, a solução deve ficar amarela). Previamente, os meios foram esterilizados em autoclave, a $121^{\circ} \mathrm{C}(1 \mathrm{~atm})$ por $20 \mathrm{~min}$. Após serem inoculados, em ambas as etapas (pré-inóculo e inóculo), o meio foi incubado a $30^{\circ} \mathrm{C}$ por $24 \mathrm{~h}$.

Com a finalidade de se obter a máxima produção de ácido propiônico, evitando a inibição característica deste tipo de fermentação, foi realizada a estratégia de conduzir uma batelada alimentada por pulsos em um reator com células imobilizadas no bagaço de sorgo. A imobilização utilizada nos ensaios foi passiva sendo utilizado o método de adsorção (Pereira Jr., et al., 2008), em um reator de imobilização.

O sistema de fermentação (Figura 1) foi constituído de dois reatores: um BioFlo (New Brunswick BioFlo 310®) com volume nominal de 1,5 L e um reator de imobilização com volume nominal de 0,12 L. O meio de fermentação utilizado foi baseado no descrito por Lewis e Yang (1992a,b) contendo por litro: $4 \mathrm{~g}$ de TSB; 0,25 K $\mathrm{KPO}_{4} ; 0,05 \mathrm{~g}$ de $\mathrm{MnSO}_{4} ; 9 \mathrm{~g}$ de extrato de levedura. Este meio foi esterilizado junto com o biorreator a $121^{\circ} \mathrm{C}(1 \mathrm{~atm})$ por 30 minutos e o 
meio contendo xilose $(40 \mathrm{~g} / \mathrm{L}$ inicial $)$ foi esterilizado a $111^{\circ} \mathrm{C}(0,5 \mathrm{~atm})$ durante $20 \mathrm{~min}$. $\mathrm{O}$ reator de imobilização, já com as células imobilizadas, foi conectado através de mangueiras ao BioFlo, que continha $1,2 \mathrm{~L}$ de meio de fermentação já esterilizado a $121^{\circ} \mathrm{C}$ por $30 \mathrm{~min}$. A bomba do biorreator foi ativada para funcionar $25 \%$ do tempo, o que corresponde a 40 minutos para que todo o meio de fermentação passasse pelo bagaço imobilizado $(1,8 \mathrm{~L} / \mathrm{h})$. A circulação do meio de fermentação no reator de imobilização para o BioFLO ocorreu de forma ascendente. Após o esgotamento do substrato, houve alimentações que se constituíram de soluções de xilose concentradas $(400 \mathrm{~g} / \mathrm{L})$, cujo volume adicionado foi calculado a fim de manter a concentração no meio em torno de $20 \mathrm{~g} / \mathrm{L}$ (50\% da concentração inicial). A influência do parâmetro temperatura também foi avaliada no presente trabalho, sendo então realizadas duas fermentações. As condições operacionais das fermentações foram pH 7 +/- 1; $150 \mathrm{rpm}$ e injeção de nitrogênio a 0,06 vvm sendo que na primeira fermentação o controle de temperatura foi desligado, já no segundo, controle de temperatura manteve-se em $30^{\circ} \mathrm{C}$ com variação de $1^{\circ} \mathrm{C}$.

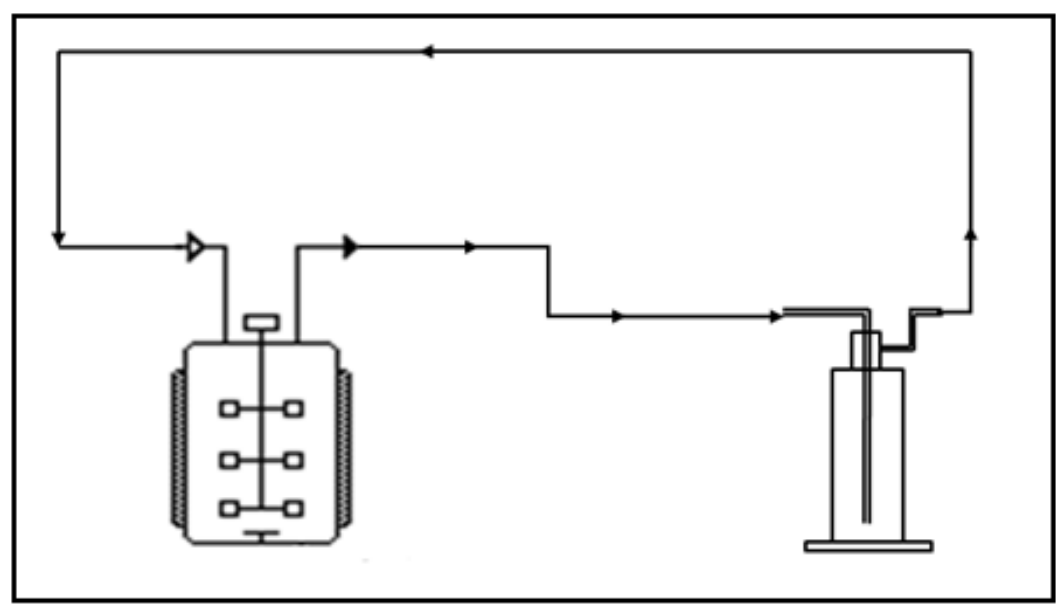

Figura 1 - Esquema da imobilização de P.acidipropionici em bagaço de sorgo

Foram coletadas amostras em intervalos de tempo regulares e estas foram devidamente tratadas para se obter os resultados de concentração de ácidos orgânicos (ácido propiônico, acético e succínico) e xilose que foram quantificadas por cromatografia líquida de alta eficiência (CLAE), em dois cromatógrafos: Shimadzu e Waters, acoplado a uma coluna PL Hi-Plex. As condições

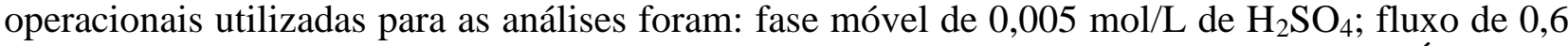
$\mathrm{mL} / \mathrm{min}$ : volume de injeção de $20 \mu \mathrm{L}$; temperatura de $60^{\circ} \mathrm{C}$ e os detectores foram o Índice de Refração para os açúcares (RID a $50^{\circ} \mathrm{C}$ ) e o Ultra-Violeta (UV/VIS) para os ácidos orgânicos. Já a quantificação celular foi realizada por turbidimetria a $600 \mathrm{~nm}$ em um espectrofotômetro UVmini 1240 - SHIMADZU.

\section{RESULTADOS E DISCUSSÕES}

Com o intuito de avaliar o parâmetro temperatura foram realizados 2 ensaios de batelada alimentada, um com a temperatura controlada e outro sem controle de temperatura. As cinéticas estão reportadas nas figuras 1 e 2 respectivamente. Cabe ressaltar que os valores estão demonstrados em massa, para permitir uma melhor visualização. 


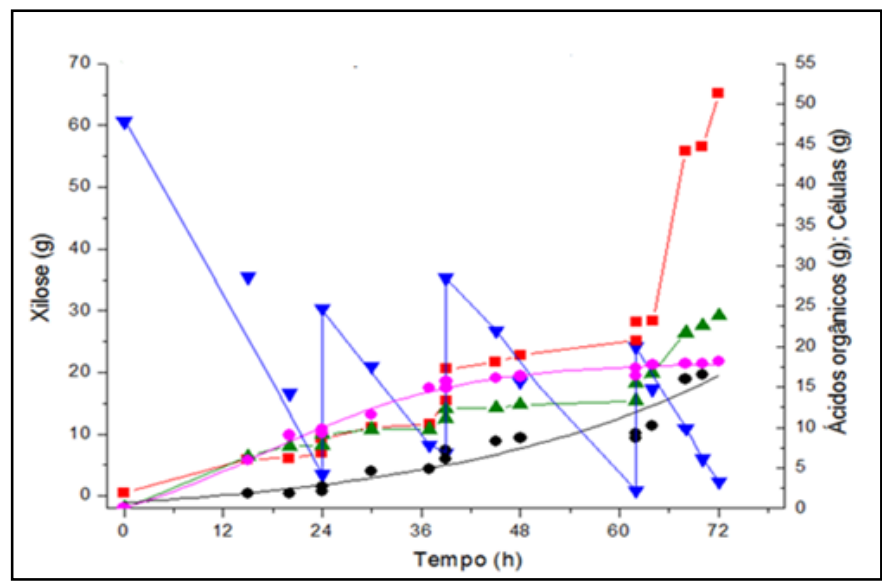

Figura 2 - Perfil cinético da batelada alimentada em biorreator empregando células imobilizadas de P. acidipropionici em bagaço de sorgo com $40 \mathrm{~g} / \mathrm{L}$ de xilose inicial e alimentações de $20 \mathrm{~g} / \mathrm{L}$, com temperatura controlada ( $\left.\mathrm{pH} 7.0,30^{\circ} \mathrm{C}, 150 \mathrm{rpm}\right)$. Legenda: $\mathbf{\nabla}$ Xilose - Ácido propiônico $\Delta$ Ácido acético • Células • Ácido Succínico

No ensaio em que se controlou a temperatura, o reator BioFlo (New Brunswick BioFlo $310^{\circledR}$ ) teve este parâmetro controlado a $30^{\circ} \mathrm{C}+/-1^{\circ} \mathrm{C}$ do início ao fim do processo. O processo teve uma duração de $72 \mathrm{~h}$ e sua produção de ácido propiônico foi de $37 \mathrm{~g} / \mathrm{L}$, já a de ácido acético e succínico foi de 17,05 g/L e 14,21 g/L, respectivamente. A produtividade volumétrica global foi de 0,51g/L.h e as razões P/A e P/S foram de 2,2:1 e 2,6:1, nessa ordem. Além disso, a eficiência do processo foi de $83 \%$ e as médias dos fatores $\mathrm{Y}_{\mathrm{P} / \mathrm{S}}$ foi de $0,41 \mathrm{~g} / \mathrm{g}$ e o $\mathrm{Y}_{\mathrm{X} / \mathrm{S}}$ foi $0,18 \mathrm{~g} / \mathrm{g}$.

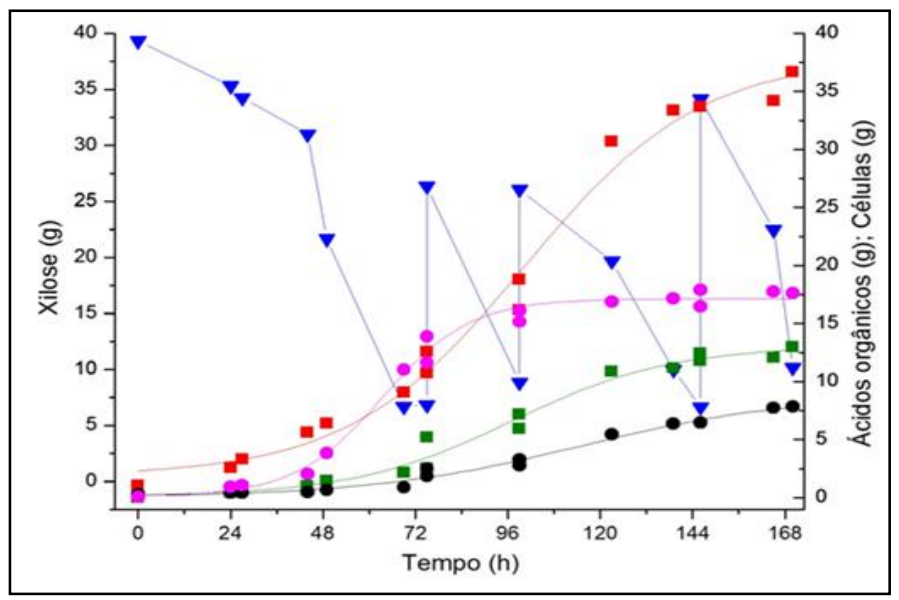

Figura 3 - Perfil cinético da batelada alimentada em biorreator empregando células imobilizadas de $P$. acidipropionici em bagaço de sorgo com $40 \mathrm{~g} / \mathrm{L}$ de xilose inicial e alimentações de $20 \mathrm{~g} / \mathrm{L}$, sem temperatura controlada (pH 7.0, $150 \mathrm{rpm})$.

Legenda: $\boldsymbol{\nabla}$ Xilose - Ácido propiônico $\boldsymbol{\Delta}$ Ácido acético • Células • Ácido Succínico

$\mathrm{Na}$ cinética de batelada alimentada sem temperatura controlada, pode-se observar que houve a produção de 26,2 g/L de ácido propiônico, 9,3 g/L de ácido acético e 5,62 g/L de ácido succínico. Além disso, atingiu-se uma produtividade volumétrica global de $0,15 \mathrm{~g} / \mathrm{L} . \mathrm{h}$, um $\mathrm{Y}_{\mathrm{X} / \mathrm{S}} \mathrm{de}$ $0,35 \mathrm{~g} / \mathrm{g}$ e uma razão P/A de 2,8:1. A razão entre ácido propiônico e succínico foi de 
aproximadamente 5:1 e houve uma produção de $64 \%$ do ácido propiônico em relação ao total de ácidos. O tempo de fermentação foi muito longo, 170 horas, e isto explica a baixa produtividade. $\mathrm{O}$ fator de rendimento em células foi de $0,29 \mathrm{~g} / \mathrm{g}$, já os fatores de rendimentos em produtos foram $0,3 \mathrm{~g} / \mathrm{g}$ (batelada inicial), 0,42 g/g (primeira alimentação), 0,61 g/g (segunda alimentação) e 0,14 g/g (terceira alimentação) ao longo das alimentações, sendo a média 0,37 g/g. Houve, também, uma eficiência de fermentação de $75 \%$.

Alguns autores como CORAL (2008) já estudaram a influência da temperatura na fermentação do ácido propiônico a partir de lactato, melaço de cana e glicerol e, com uma temperatura de $30^{\circ} \mathrm{C}$. Este autor alcançou valores de concentração de ácido propiônico de 15,06 $\mathrm{g} / \mathrm{L}, 7,55 \mathrm{~g} / \mathrm{L}$ e $6,77 \mathrm{~g} / \mathrm{L}$, respectivamente, superiores aos encontrados em $36^{\circ} \mathrm{C}(13,32 \mathrm{~g} / \mathrm{L}, 3,71$ $\mathrm{g} / \mathrm{L}$ e $4,87 \mathrm{~g} / \mathrm{L}$ respectivamente), além de um aumento na razão $\mathrm{P} / \mathrm{A}$ com a temperatura de $36^{\circ} \mathrm{C}$ em relação a de $30^{\circ} \mathrm{C}$. Seus resultados vão ao encontro dos conseguidos na presente pesquisa e demonstram a importância do controle de temperatura. Em relação à batelada alimentada com células imobilizadas, outros autores também desenvolveram trabalhos, como LIANG et al, 2012, que realizaram experimento em batelada alimentada com células imobilizadas e conseguiram uma produção de ácido propiônico de 68,9 g/L em um tempo de 200 h, com uma produtividade volumétrica de 0,34 g/L.h. Cabe destacar aqui, que a produtividade do presente trabalho foi de $0,51 \mathrm{~g} / \mathrm{L} . \mathrm{h}$ e com alimentações de $20 \mathrm{~g} / \mathrm{L}$ de xilose em contraste a um outro trabalho que utilizou $20 \mathrm{~g} / \mathrm{L}$ de glicose e $40 \mathrm{~g} / \mathrm{L}$ de frutose.

Uma comparação mais explícita dos dados encontrados nestes 2 experimentos pode ser observada no gráfico de barras (Figura 4), no qual é mostrado a diferença entre as produtividades volumétricas e as produções de ácido propiônico, evidenciando a importância do controle da temperatura nesta fermentação.

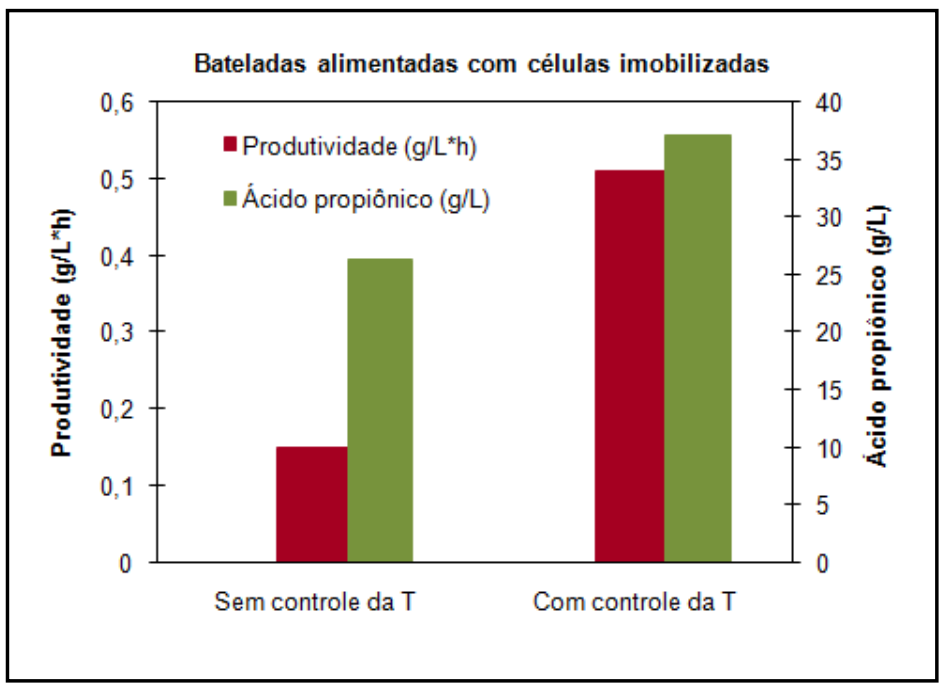

Figura 4 - Gráfico comparativo entre as bateladas alimentadas sem controle de temperatura e com controle de temperatura.

Legenda: - Produtividade - Ácido propiônico 


\section{CONCLUSÃO}

Ao serem comparados os dois processos de batelada alimentada com células imobilizadas, onde foi estudado o controle de temperatura, pode-se observar que na fermentação conduzida com controle de temperatura, obteve-se um aumento de cerca de $41 \%$ na produção de ácido propiônico ( $37 \mathrm{~g} / \mathrm{L}$ de ácido propiônico em comparação com $26 \mathrm{~g} / \mathrm{L}$ ), com um decréscimo de $57 \%$ no tempo (170 horas sem controle de temperatura para 72 horas de processo ao se controlar este parâmetro). Além disso, a temperatura também influenciou na razão entre ácido propiônico e ácido acético produzidos. Desta forma, fica evidente a importância do parâmetro temperatura na batelada alimentada utilizando células imobilizadas para a produção de ácido propiônico.

\section{REFERÊNCIAS}

CORAL, J., KARP, SG., PORTO DE SOUZA VANDENBERGHE, L., PARADA, JL., PANDEY, A., SOCCOL, CR. 2008. Batch fermentation model of propionic acid production by Propionibacterium acidipropionici in different carbon sources. Appl Biochem Biotechnol. Dec;151(2-3):333-41.

LEWIS V.P., YANG S.T., 1992a. Continuous propionic acid fermentation by immobilized Propionibacterium acidipropioniciin a novel packed-bed bioreactor. Biotechnol Bioeng 40:465474.

LEWIS VP, YANG S-T. 1992b. Continuous propionic acid fermentation by using immobilized Propionibacterium acidipropionici in a novel packed-bed bioreactor. Biotechnol Bioeng 40:465474.

PEREIRA JR, N.; COUTO, M. A. P. G.; SANTA ANNA, L. M. M. (2008b). Biomass of lignocellulosic compostion for fuel ethanol production and the context of biorefinery. Series on Biotechnology.BibliotecaNacional: Rio de Janeiro, v. 2, 2008.

LIANG X.L.; LI., L., LI, SHUANG L.; CAI YH.; YANG, ST.; WANG JF. 2012. Enhanced propionic acid production from Jerusalem artichoke hydrolysate by immobilized Propionibacterium acidipropionici in a fibrous-bed bioreactor. Bioprocess Biosyst. Eng. 35: 915921 